\title{
CRP1, a Protein Localized in Filopodia of Growth Cones, Is Involved in Dendritic Growth
}

\author{
Liping Ma, ${ }^{1}$ Jeffrey A. Greenwood, ${ }^{2}$ and Melitta Schachner ${ }^{1,3}$ \\ ${ }^{1}$ W. M. Keck Center for Collaborative Neuroscience and Department of Cell Biology and Neuroscience, Rutgers, The State University of New Jersey, \\ Piscataway, New Jersey 08854, ${ }^{2}$ Department of Biochemistry and Biophysics, Oregon State University, Corvallis, Oregon 97331-7305, and ${ }^{3}$ Center for \\ Neuroscience, Shantou University Medical College, Shantou 515041, Peoples Republic of China
}

The cysteine-rich protein (CRP) family is a subgroup of LIM domain proteins. CRP1, which cross-links actin filaments to make actin bundles, is the only CRP family member expressed in the CNS with little known about its function in nerve cells. Here, we report that CRP1 colocalizes with actin in the filopodia of growth cones in cultured rat hippocampal neurons. Knockdown of CRP1 expression by short hairpin RNA interference results in inhibition of filopodia formation and dendritic growth in neurons. Overexpression of CRP1 increases filopodia formation and neurite branching, which require its actin-bundling activity. Expression of CRP1 with a constitutively active form of Cdc42, a GTPase involved in filopodia formation, increases filopodia formation in COS-7 cells, suggesting cooperation between the two proteins. Moreover, we demonstrate that neuronal activity upregulates CRP1 expression in hippocampal neurons via Ca ${ }^{2+}$ influx after depolarization. $\mathrm{Ca}^{2+} /$ calmodulin-dependent protein kinase IV (CaMKIV) and cAMP response element binding protein mediate the $\mathrm{Ca}^{2+}$-induced upregulation of CRP1 expression. Furthermore, CRP1 is required for the dendritic growth induced by $\mathrm{Ca}^{2+}$ influx or CaMKIV. Together, these data are the first to demonstrate a role for CRP1 in dendritic growth.

\section{Introduction}

Filopodia are finger-like, plasma membrane protrusive structures composed of tightly oriented parallel actin bundles that extend radially from the lamellipodial actin meshwork at the leading edge of a motile cell. A critical step in filopodia formation is the cross-linking of actin filaments, as a single actin filament lacks the stiffness needed to advance the cell membrane (Mogilner and Oster, 1996; Mogilner and Rubinstein, 2005). Filopodia play critical roles in various physiological processes, such as cell migration, wound healing, and neurite outgrowth (Mattila and Lappalainen, 2008). In neurons, the extension of axons and dendrites is led by growth cones tipped by filopodia, which are proposed to function both in sensing guidance cues and in facilitating locomotion (for review, see Dickson, 2002). The importance of filopodia formation in neuritogenesis has been demonstrated by experiments showing that the loss of filopodia formation causes defects in neurite formation (Dent et al., 2007) and that motile filopodia initiate neurite branching (Gallo and Letourneau, 2004; Lalli and Hall, 2005). Filopodia also serve as precursors for dendritic spines in neurons (Mattila and Lappa-

\footnotetext{
Received May 25, 2011; revised Sept. 23, 2011; accepted Sept. 26, 2011.

Author contributions: L.M. and M.S. designed research; L.M. performed research; J.A.G. contributed unpublished reagents/analytic tools; L.M. analyzed data; L.M., J.A.G., and M.S. wrote the paper.

This work was supported by New Jersey Commission on Spinal Cord Research Grant 05-3048-SCR-E-0 (M.S.). M.S. is a consultant at the Center for Neuroscience of Shantou University Medical College. We are grateful to R. Maurer, M. E. Greenberg, R. Goodman, M. Laiho, B. L. Firestein, A. R. Means, and Y. Wang for kindly providing plasmids. We also thank S.-C. Hsu and, in particular, K. M. Gibbs for very helpful comments on this manuscript.

The authors declare no competing financial interests.

Correspondence should be addressed to Melitta Schachner, W. M. Keck Center for Collaborative Neuroscience, 604 Allison Road, Piscataway, NJ 08854. E-mail: schachner@biology.rutgers.edu.

DOI:10.1523/JNEUROSCI.2595-11.2011

Copyright $\odot 2011$ the authors $\quad 0270-6474 / 11 / 3116781-11 \$ 15.00 / 0$
}

lainen, 2008). However, the mechanisms for filopodia formation are not fully understood.

The cysteine-rich protein (CRP) family is a subgroup of the LIM-domain protein family in vertebrates and includes CRP1 (encoded by CRP1/csrp1 gene), CRP2, and CRP3/MLP (muscle LIM-domain protein) (Louis et al., 1997). All three CRP family members have been reported to localize to the nucleus (Chang et al., 2003; Kadrmas and Beckerle, 2004) and interact with $\alpha$-actinin and zyxin (Schmeichel and Beckerle, 1994; Arber and Caroni, 1996; Louis et al., 1997; Pomies et al., 1997). Whereas CRP2 and CRP3 expression is limited to muscle cells (Jain et al., 1998), CRP1 is expressed in multiple adult organs and is the only member with detectable expression in the mammalian CNS (McLaughlin et al., 1994; Jain et al., 1998).

Based on evidence from our laboratory that CRP1 is needed for functional recovery after spinal cord injury in the adult zebrafish (our unpublished observations), we wanted to assess its function in the mammalian CNS. CRP1 has been reported in many different cellular functions: acting as a transcriptional cofactor (Chang et al., 2003), suppressing cell proliferation, protecting cells from stress-induced death (Latonen et al., 2008), regulating cell movement during zebrafish development (Miyasaka et al., 2007), and promoting neointima formation (Lilly et al., 2010). It has also been demonstrated that CRP1 regulates actin filament bundling via direct interaction with actin (Tran et al., 2005; Jang and Greenwood, 2009). However, little is known about its function in the CNS. In the present study, we report a role for CRP1 in filopodia formation and dendritic growth, which depends, at least partly, on its actin-bundling activity. The role of CRP1 in filopodia formation is regulated by the Cdc42 pathway. In addition, we show that CRP1 is upregulated by $\mathrm{Ca}^{2+}$ 
influx via the $\mathrm{Ca}^{2+} /$ calmodulin-dependent protein kinase IV (CaMKIV)-cAMP response element binding protein (CREB) pathway and is involved in $\mathrm{Ca}^{2+}$-dependent dendritic growth in neurons. Collectively, our data provide the first functional characterization of CRP1 in the CNS.

\section{Materials and Methods}

Neuronal cell culture. Primary hippocampal neurons were prepared as described previously (Crozier et al., 2008). Hippocampi from embryonic day 18 rat embryos of either sex were digested with $0.25 \%$ trypsin-EDTA for $10 \mathrm{~min}$ at $37^{\circ} \mathrm{C}$, followed by trituration with a firepolished Pasteur pipette in the plating medium (Neurobasal with 10\% fetal bovine serum; Invitrogen). Neurons were plated onto coverslips coated with poly-D-lysine $(100 \mu \mathrm{g} / \mathrm{ml}$; Sigma $)$ and laminin $(10 \mu \mathrm{g} / \mathrm{ml}$; Invitrogen). For some experiments (Fig. 1), to show the morphology of growth cones, neurons were plated onto coverslips coated only with poly-D-lysine. Four hours after plating, the medium was changed to Neurobasal with $2 \%$ B27 (for nontransfected neurons) or serum-free medium (SFM; for transfected neurons) (Crozier et al., 2008) with $0.5 \%$ FBS (Invitrogen). SFM consisted of a 1:1 (v/v) mixture of Ham's F-12 (Invitrogen) and MEM (Invitrogen) and was supplemented with $25 \mu \mathrm{g} / \mathrm{ml}$ insulin, $100 \mu \mathrm{g} / \mathrm{ml}$ transferrin, $60 \mu \mathrm{M}$ putrescine, $20 \mathrm{~nm}$ progesterone, $30 \mathrm{~nm}$ selenium, $6 \mathrm{mg} / \mathrm{ml}$ glucose, $0.5 \mathrm{U} / \mathrm{ml}$ penicillin, and $0.5 \mathrm{mg} / \mathrm{ml}$ streptomycin. Dissociated neurons were transfected by electroporation using the Amaxa Nucleofector device (Lonza) immediately after dissociation. Cotransfection of control shRNA (CON) or CRP1 shRNA (shCRP1) with p-CAG-DsRed was done at a ratio of 3:1, and cotransfection of CRP1 shRNA and a silent mutant of CRP1 (smCRP1) was done at a ratio of $2: 1$. For all cotransfection experiments, the ratio was based on the total amount of plasmid DNA (in micrograms). Neuronal morphology of transfected neurons was analyzed $3 \mathrm{~d}$ after plating.

The potassium chloride $(\mathrm{KCl})$ treatment was performed as described previously (Redmond et al., 2002). Dissociated neurons were cultured on poly-D-lysine-coated coverslips or well plates at 15,000 per square centimeter in Neurobasal medium containing 2\% B27. At $3 \mathrm{~d}$ in vitro (DIV), neurons were stimulated with $50 \mathrm{~mm} \mathrm{KCl}$ for the indicated time. Inhibitors APV (200 $\mu \mathrm{M}$; Sigma), nifedipine (20 $\mu \mathrm{M}$;

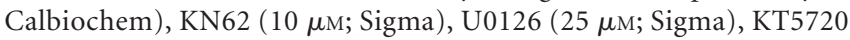
( $5 \mu \mathrm{M}$; Sigma), and EGTA ( $2 \mathrm{~mm}$; Sigma) were added $30 \mathrm{~min}$ before the addition of $\mathrm{KCl}$ (Redmond et al., 2002). For experiments involving $\mathrm{KCl}$ treatment or CaMKIV overexpression, hippocampal neurons were transfected at 2 DIV using Effectene (QIAGEN). Transfected neurons were treated with $50 \mathrm{~mm} \mathrm{KCl}$ at $3 \mathrm{DIV}$ for $2 \mathrm{~d}$ and fixed at 5 DIV. Cotransfection of CaMKIV and CRP1 shRNA or control shRNA was done at a ratio of $2: 1$, and neurons were fixed and analyzed at 5 DIV.

$\mathrm{N} 2 \mathrm{a}$ cells were cultured in DMEM with $1 \mathrm{~mm}$ sodium pyruvate and $10 \%$ FBS (Invitrogen). COS-7 cells were cultured in DMEM with $10 \%$ FBS. N2a or COS-7 cells were transfected with Fugene 6 (Roche) or Lipofectamine 2000 (Invitrogen) according to the manufacturer's instructions. Transfected COS-7 cells were stained for actin filaments to show filopodia morphology. Cells with a minimum of 20 filopodia measuring at least $5 \mu \mathrm{m}$ in length were scored as being "with filopodia," and all other cells were scored as being "without filopodia" as described pre-

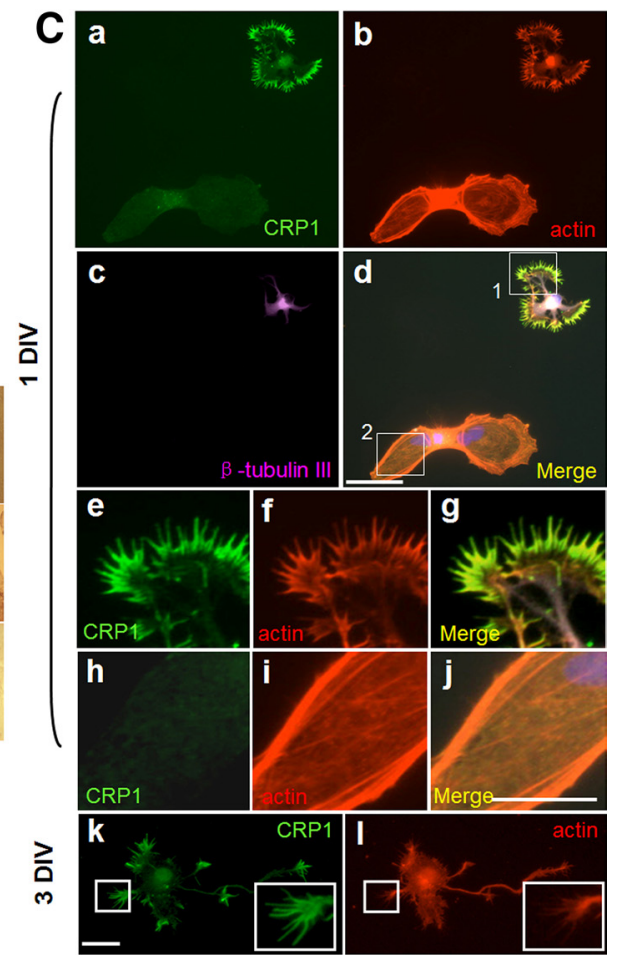

1. Expression of CRP1 in the adult mouse CNS and cultured primary hippocampal neurons. A, CRP1 protein is widely

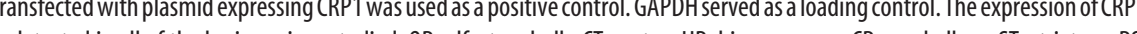
is expressed in neurons that are $\beta$-tubulin III positive (c) and is weakly expressed in non-neuronal cells that are $\beta$-tubulin III enlargements of the growth cone. $\boldsymbol{C} \boldsymbol{e} \boldsymbol{g}$ are enlargements of boxed area 1 , and $\boldsymbol{h}-\boldsymbol{j}$ are enlargements of boxed area $2 . n=3$ experiments. Scale bars: $\boldsymbol{B}, \boldsymbol{C} \boldsymbol{a}-\boldsymbol{d}, \boldsymbol{C} \boldsymbol{k}, \boldsymbol{C l}, 50 \mu \mathrm{m} ; \boldsymbol{C} \boldsymbol{e}-\boldsymbol{j}, 25 \mu \mathrm{m}$.

viously (Gauthier-Campbell et al., 2004). At least 500 cells from five different fields were scored for each treatment. Transfection experiments were performed in quadruplicate, and all experiments were repeated three times.

DNA constructs. Mouse CRP1 was subcloned into pEGFP-N1 vector (Clontech) using NheI and BamH I. Wild-type (full-length) CRP1, residues 1-79 of CRP1, and residues 1-65 of CRP1 were described previously (Jang and Greenwood, 2009). CaMKIV-313 [constitutively active CaMKIV (caCaMKIV)] and CaMKII-290 [constitutively active CaMKII (caCaMKII)] were gifts from Dr. R. Maurer (Oregon Health Sciences University, Portland, OR). CaMKIV-200A [dominant-negative CaMKIV (dnCaMKIV)] was a gift from Dr. A. R. Means (Duke University Medical Center, Durham, NC). KCREB (dominant negative for CREB) was a gift from Dr. M. E. Greenberg (Harvard Medical School, Boston, MA). A constitutive form of Cdc42 (pRK5myc Cdc42 L61) was obtained from Addgene (Cambridge, MA; Dr. A. Hall's laboratory). Quantitative PCR was used to analyze mRNA expression levels of exogenous genes (caCaMKIV, caCaMKII, dnCaMKIV, and KCREB) in our cell culture system. After transfection, substantial upregulation of these exogenous genes was observed when compared with the GFP control group. Comparable levels of expression were obtained for caCaMKIV and caCaMKII, which is expected since the expression of these genes is under the control of the same promoter in the same vector.

pSUPER-GFP (Oligoengine) was used to make shRNA. The siRNA sequence used for mouse and rat CRP1 (5'-GGGAAGTCCTGGCATA 
AGT-3') and the nonsense sequence used as the negative control (5'-GC GCGCTATGTAGGATTCG-3') were subcloned into pSUPER-GFP vector according to the manufacturer's instructions. To knock down the endogenous CRP1 expression in COS-7 cells, annealed siRNA for monkey CRP1 (sense, 5' -GGGCAUCAAGCACGAGGAAtt-3'; antisense, 5' UUCCUCGUGCUUGAUGCCCag- $3^{\prime}$ ) was used.

A silent mutant of CRP1 (see Fig. $3 A$ ), was constructed using the QuickChange Lighting site-directed mutagenesis kit (Stratagene).

Immunostaining. For immunostaining, neurons were fixed in freshly prepared $4 \%$ paraformaldehyde in $0.1 \mathrm{~m}$ phosphate buffer, $\mathrm{pH} 7.4$, for 20 min. The cells were blocked and permeabilized with $3 \%$ donkey serum, $1 \%$ bovine serum albumin (BSA), and $0.2 \%$ Triton X-100 in PBS, which was followed by incubation with anti-CRP1 antibody (1:200; Santa Cruz Biotechnology) and/or anti- $\beta$-tubulin III (1:500; Covance Research Products) at $4^{\circ} \mathrm{C}$ overnight. Cells were then incubated for $2 \mathrm{~h}$ with the secondary antibody (Alexa Fluor 488-conjugated anti-goat antibody, 1:800; Invitrogen) diluted in PBS containing $1 \%$ BSA and $0.2 \%$ Triton $\mathrm{X}-100$. For double staining of CRP1 and $\beta$-tubulin III, the cells were then incubated with Cy5-conjugated anti-mouse IgG (1:800; Invitrogen) after three washes. For the negative control, the primary antibody was replaced with normal goat IgG (Sigma). Phalloidin coupled to Texas Red (Invitrogen) was used to label actin filaments.

The CRP1 antibody used for immunostaining detects one single band of the expected apparent molecular weight by Western blot analysis in N2a neuroblastoma cells overexpressing CRP1, demonstrating the specificity of this antibody. The specificity of CRP1 antibody was also supported by evidence showing that a much stronger signal for CRP1 was obtained by immunostaining of N2a cells transfected with the CRP1 plasmid when compared with those transfected with GFP (data not shown).

RNA isolation and quantitative real-time PCR. Total RNA was isolated using the RNeasy Micro kit (QIAGEN) according to the manufacturer's directions. The concentration of extracted total RNA was determined with a NanoDrop spectrophotometer (NanoDrop Technologies). One microgram of total RNA was reverse transcribed with SuperScript II Reverse Transcriptase (Invitrogen). Then, $2 \mathrm{ng}$ of cDNA was used for each quantitative real-time PCR with a final volume of $10 \mu \mathrm{l}$ containing primers and Power SYBR Green PCR master mix (Applied Biosystems). Quantitative real-time PCR ( $\mathrm{PPCR}$ ) was performed as described previously (Goff et al., 2004). The comparative cycle threshold $\mathrm{C}_{\mathrm{t}}$ method $\left(\Delta \Delta \mathrm{C}_{\mathrm{t}}\right.$ method) was used for data analysis. Two reference control genes, $18 \mathrm{~S}$ rRNA and GAPDH, were tested under the different experimental conditions in this study. Since GAPDH showed less variation between treatments compared with $18 \mathrm{~S}$ rRNA, GAPDH was used as an endogenous control gene for all qPCR experiments in this study. No significant variation of GAPDH gene expression was detected between control and treated samples, when the same amount of cDNA was used. Data from the control group was set as 1 or $100 \%$, and normalized relative quantities were shown. The primers used are as follows: CRP1 (forward, $5^{\prime}-$ ACCACCAACCCCAATGCAT-3'; reverse. 5' -AGAAGATCGGCGGCT CTGAG-3') and GAPDH (forward, 5'-TCCTGCACCACCAACTG CTTAGCC-3'; reverse, 5' -GTTCAGCTCTGGGATGACCTTGCC-3').

In situ hybridization. Digoxigenin (DIG)-labeled RNA sense and antisense probes for mouse CRP1 (NM_007791, full length) were generated using the Megascript system (Ambion) according to the manufacturer's protocol, and in situ hybridization was performed as described previously (Becker et al., 1998; Lieberoth et al., 2003). In brief, $20 \mu$ m-thick sagittal brain sections were incubated with $0.1 \mathrm{~N} \mathrm{HCl} \mathrm{for} 10 \mathrm{~min}$, followed by three washes in PBS, pH 7.4, and digested for $10 \mathrm{~min}$ with $10 \mu \mathrm{g} / \mathrm{ml}$ proteinase-K (Roche) at room temperature, followed by fixation in $4 \%$ paraformaldehyde after two washes with glycine $(2 \mathrm{mg} / \mathrm{ml})$ in PBS, $\mathrm{pH}$ 7.4. Next, the sections were acetylated, dehydrated, air dried, prehybridized, and subsequently hybridized with DIG-labeled probe at $55^{\circ} \mathrm{C}$ overnight. The hybridized probes were detected using alkaline phosphatase-coupled anti-DIG antibody (Roche) and color developed with nitro-blue tetrazolium and 5-bromo-4-chloro-3-indolyl phosphate (Roche).

Western blot analysis. Goat anti-CRP1 [1:500 (Santa Cruz Biotechnology) or 1:400 (R\&D Systems)] or mouse anti-GAPDH (1:1000; Millipore) was used as the primary antibody. HRP-conjugated donkey anti-goat (1:5000; Promega) or HRP-conjugated goat anti-mouse (1: 5000; Millipore) was used as the secondary antibody. The ECL detection system (Pierce Chemical) was used for signal detection. Quantitative analysis was performed using Kodak molecular imaging software version 4.0 (Carestream Health).

Image analysis. Images of transfected neurons were captured using a digital CCD camera attached to an inverted microscope driven by AxioVision software (Carl Zeiss). Transfection experiments were performed in duplicate wells, and all experiments were repeated at least three times. Approximately 15-20 neurons per group were obtained each time, and GFP or DsRed expression was used to visualize the cell morphology. Captured neurons were traced and analyzed using ImageJ and Scion Image software as described previously (Dityatev et al., 2000). Since hippocampal neurons have not developed dendritic spines at 3-5 DIV, all long thin structures emerging from neurites shorter than $10 \mu \mathrm{m}$ were counted as filopodia, and others (longer than $10 \mu \mathrm{m}$ ) were counted as branches as described previously (Li et al., 2008). Processes originating from cell body were recognized as primary neurites, and branches were those originating from neurites. The longest process was recognized as an axon, and the shorter processes were recognized as dendrites as described by Garvalov et al. (2007). In this study, the term "neurite" is used for both dendrites and axons. Total dendritic length represents the total length of all dendrites per neuron, and total dendritic tips represent the total number of all dendritic processes and branches per neuron. Data are shown as mean values \pm SEM. Depending on the number of groups and independent factors, data were analyzed with the two-tailed Student's $t$ test, one-way ANOVA, or two-way ANOVA followed by Tukey's post hoc test when appropriate, with the level of significance set at $p<0.05$.

\section{Results}

\section{CRP1 colocalizes with actin in filopodia of growth cones in cultured hippocampal neurons}

Since little is known about the expression and function of CRP1 in the nervous system, the expression of CRP1 was first investigated in the adult mouse CNS using Western blot analysis. A previous report showed that the expression of CRP1 mRNA increases as the brain develops and reaches its highest expression in the adult brain (McLaughlin et al., 1994). Expression of CRP1 protein was detected in all brain regions studied, including the olfactory bulb, cortex, hippocampus, striatum, cerebellum, brain stem, and spinal cord (Fig. 1A). In situ hybridization confirmed the widespread expression of CRP1 and showed that neurons in the cerebral cortex, hippocampus, and cerebellar Purkinje cells were positive for CRP1 mRNA (Fig. $1 B$ ). We were unable to detect CRP1 protein using immunohistochemistry. However, CRP1 protein was detected by immunostaining in cultured rat hippocampal neurons as early as 1 DIV. In neurons cultured on coverslips coated with poly-D-lysine and laminin, localization of CRP1 was observed at the tips of neurites (data not shown). To determine the localization of CRP1 within the growth cone, neurons were cultured on coverslips coated only with poly-D-lysine. It was found that CRP1 colocalized with actin filaments in filopodia of the growth cones (Fig. 1C). The location of CRP1 in filopodia, which are composed of bundled actin, is consistent with a report showing that CRP1 acts as an actin-bundling protein (Tran et al., 2005). The distribution of CRP1 in neurons at 3 DIV was similar to that of neurons at 1 DIV (Fig. $1 C k, l)$. However, the localization of CRP1 was different in $\beta$-tubulin IIInegative non-neuronal cells. Although a weak signal for CRP1 was observed in the cell body of these cells, no colocalization of CRP1 and actin filaments was detected (Fig. $1 C h-j$ ). The distinct localization to the filopodia of neuronal cells suggests a specific function for CRP1 in the neuronal growth cone. 


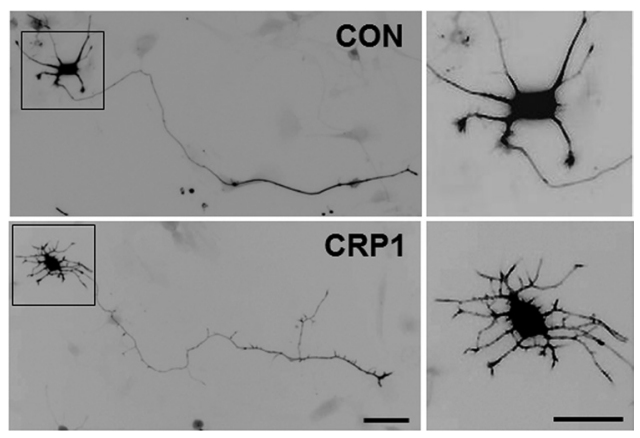

Figure 2. Overexpression of CRP1 increases branches and filopodia on neurites. Neuronal morphology was analyzed $3 \mathrm{~d}$ after transfection with nulceofector. CRP1-transfected neurons have more branches and filopodia along their neurites when compared with GFP-transfected neurons. $n=3$ experiments. Scale bars: $50 \mu \mathrm{m}$; enlargements, $25 \mu \mathrm{m}$.

\section{CRP1 is involved in dendritic growth}

The localization of endogenous CRP1 in cultured neurons indicates a potential function in filopodia, which are involved in neurite growth. We next studied whether CRP1 has an effect on neuronal morphology. The function of CRP1 in neurons was first investigated in gain-of-function experiments. We transfected neurons with GFP-CRP1 or control GFP vectors immediately after dissociation, and neuronal morphology was examined at 3 DIV. Similar to what has been reported previously, the GFP tag did not alter the function and location of CRP1 (Tran et al., 2005). No statistically significant change in total neurite length per neuron (CON, $589 \pm 73 \mu \mathrm{m}, n=60$ neurons; CRP1, $643 \pm$ $102 \mu \mathrm{m}, n=60$ neurons; $t$ test, $p>0.05$ ) or in the length of the longest neurite was induced by CRP1 expression. However, the number of neuritic branches per cell was increased by expression of CRP1 in hippocampal neurons (CON, $7.9 \pm 0.8, n=60$ neurons; CRP1, $17 \pm 1.6, n=60$ neurons; $t$ test, $p<0.05$ ) (Fig. 2 ), which is consistent with the role of motile filopodia in the initiation of neurite branching (Gallo and Letourneau, 2004; Lalli and Hall, 2005). CRP1 expression was also observed to increase the total number of filopodia per $100 \mu \mathrm{m}$ of neurites $(\mathrm{CON}, 1.44 \pm 0.19$ per $100 \mu \mathrm{m}$ neurite, $n=60$ neurons; CRP1, $4.17 \pm 0.42$ per $100 \mu \mathrm{m}$ neurite, $n=60$ neurons; $t$ test, $p<0.05$ ) (Fig. 2). These data provide evidence for the role of CRP1 in filopodia formation.

Since there is endogenous expression of CRP1 in hippocampal neurons, its function was also tested in loss-of-function experiments, in which RNA interference was used to reduce the expression of CRP1. A shRNA sequence against both mouse and rat CRP1 was designed and incorporated into the pSUPER-GFP vector (Chen and Firestein, 2007). The negative control shRNA with no potential mRNA target did not show any toxic effects when used in cultured neurons as reported previously (Li et al., 2008). To study the specificity of the CRP1 shRNA, we made a silent mutant CRP1 in which six nucleotides in the shRNA sequence were replaced by neutral nucleotides (Fig. 3A) to express an mRNA that codes for the same protein as the wild-type CRP1 but could not be targeted by the CRP1 shRNA as evidenced by qPCR (data not shown). This shRNA resistance of smCRP1 was also investigated by Western blot analysis. Since the exogenous CRP1 is tagged with GFP, it was easy to distinguish exogenous from endogenous CRP1 expression based on their different molecular weights. As shown in Figure 3B, the CRP1 shRNA reduced protein levels of both endogenous and exogenous CRP1 from wildtype CRP1 plasmid, but not the CRP1 protein expression from the silent mutant CRP1 plasmid. The CRP1 shRNA also reduced the expression of endogenous CRP1 in hippocampal neurons (Fig. 3C).

Hippocampal neurons were transfected with either shCRP1 or CON or with CRP1 shRNA and smCRP1 together immediately after dissociation, and neuronal morphology was analyzed 3 d later. Neither shRNA affected cell viability (data not shown). The number of primary neurites in neurons transfected with shCRP1 was decreased compared with neurons transfected with the negative control shRNA (Fig. $3 D, E$ ), consistent with the potential function of CRP1 in neuritogenesis. Knockdown of CRP1 also reduced the number of neuritic branches (Fig. $3 F$ ) and filopodia (Fig. 3G). Moreover, the total length of neurites was reduced in neurons transfected with shCRP1 compared with control shRNA (Fig. $3 H$ ). Typically, cultured hippocampal neurons have established axon-dendrite polarization at 3 DIV with neurons exhibiting several minor processes and one major process with the longest length. The major process is positive for taul, an axonal marker, and thus identified unequivocally as an axon (Dotti et al., 1988; Zhang et al., 2007). Here, the longest process was recognized as an axon as described previously (Lebrand et al., 2004; Garvalov et al., 2007). It was found that shCRP1 did not affect the length of the longest process (Fig. $3 J$ ), suggesting that CRP1 is involved in dendritic (Fig. 3I) rather than axonal growth in hippocampal neurons. As expected, the reduced dendritic growth was rescued by cotransfection with smCRP1 (Fig. 3D-J), demonstrating the specificity of CRP1 shRNA. Whereas knockdown of CRP1 decreased the length of total neurites, overexpression of CRP1 did not lead to enhanced neurite length, suggesting that CRP1 expression is necessary but not sufficient for typical neurite outgrowth.

\section{Role of CRP1 actin-bundling activity in dendritic growth and the regulation of the $\mathrm{Cdc} 42$ pathway on CRP1 function}

CRP1 consists two LIM domains (LIM1, LIM2), each followed by a glycine-rich region (GR1, GR2) (Fig. 4A). Previously, it was thought that CRP1 did not directly bind to actin filaments but associated indirectly through other actin-binding proteins, like $\alpha$-actinin and zyxin (Sadler et al., 1992; Pomies et al., 1997; Schmeichel and Beckerle, 1998). However, CRP1 has been shown to bind directly and bundle actin filaments, independently of $\alpha$-actinin and zyxin (Tran et al., 2005; Jang and Greenwood, 2009). Using truncated forms of CRP1, the LIM1 and GR1 domains were determined to contain the actin-bundling activity (Tran et al., 2005; Jang and Greenwood, 2009). Since overexpression of CRP1 in neurons increased the number of neurite branches and filopodia in our study, we next investigated the role of actin-bundling activity using various segments of CRP1. Truncated forms of CRP1 tagged with GFP were used as reported (Fig. 4A) (Jang and Greenwood, 2009). Residues 1-79 of CRP1 contain the LIM1 and GR1 domains and retain actin-bundling ability, whereas residues $1-65$, which only contain the LIM1 domain, lose this function (Jang and Greenwood, 2009). Hippocampal neurons were transfected immediately after dissociation, and neuronal morphology was analyzed $3 \mathrm{~d}$ later. Overexpression of residues 1-79 increased the number of neuritic branches (Fig. $4 B, C$ ) and filopodia (Fig. $4 B, D$ ) to the level of the wild-type CRP1 when compared with the GFP control group, whereas overexpression of residues 1-65 was comparable to control (Fig. $4 B-D)$. Thus, the ability of CRP1 in regulating neurite branching and filopodia formation is mediated, at least partly, by its actinbundling activity.

Our findings suggest that CRP1 affects neuronal morphology via its actin-bundling activity in filopodia formation. The role for 
A shCRP1 $-1---1$ GGGAATCCTGGCATAAGT----
wtCRP1 GATCGGTGCCGGAAGTCCTGGCATAAGTCCTGCTTCCG
smCRP1 GATCGGTGCCGGTAAAAGTTGGCACAAATCCTGCTTCCG

B

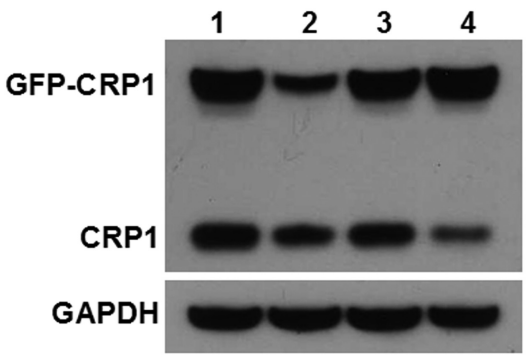

1, CON+wtCRP1; 2, shCRP1+wtCRP1; 3, CON+smCRP1; 4, shCRP1+smCRP1

D
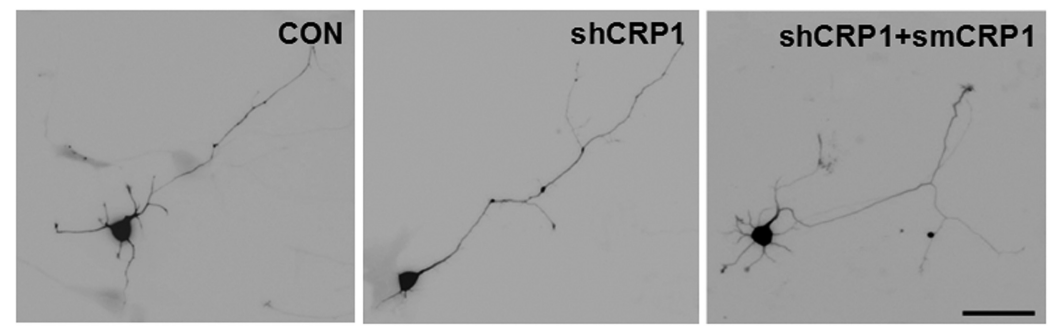

E

$\mathbf{F}$
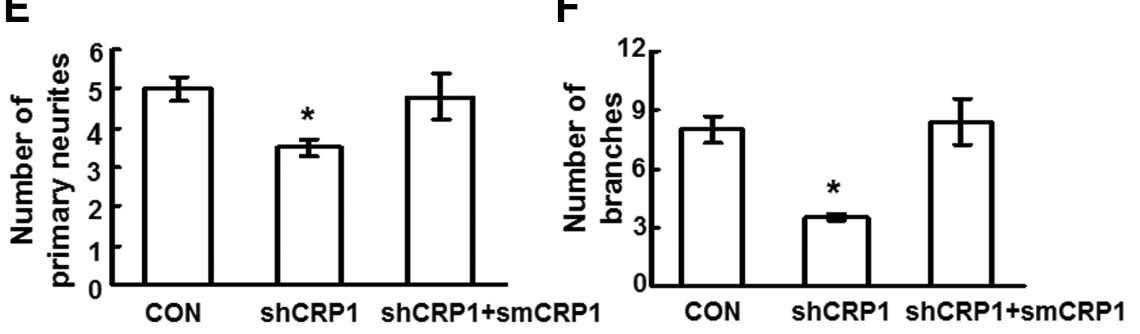

G

H
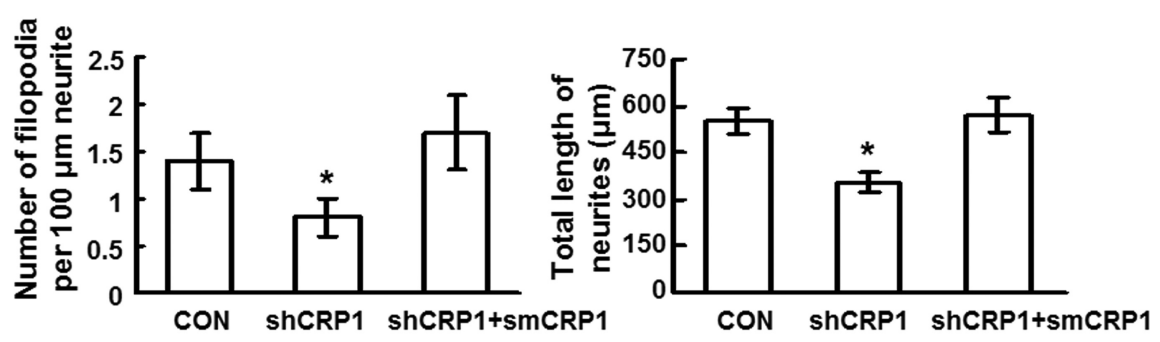

I

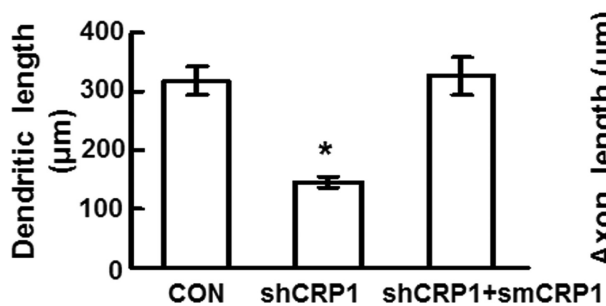

$\mathbf{J}$

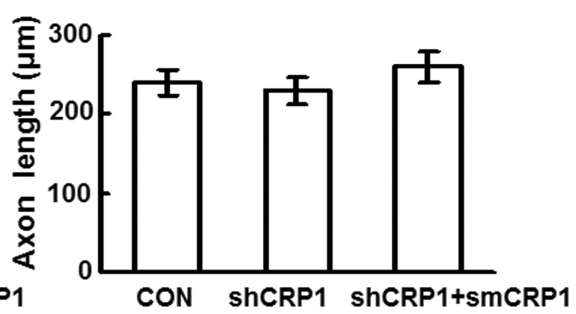

Figure 3. CRP1 is required for dendritic growth in hippocampal neurons. A, Sequences of shCRP1, wild-type CRP1 (wtCRP1), and $s m C R P 1$. Whereas smCRP1 expresses the same protein as wtCRP1, smCRP1 contains six mutated neutral nucleotides compared with wtCRP1. B, Effect of shCRP1 on protein expression levels of wtCRP1 and smCRP1. N2a cells were cotransfected with the indicated vectors. Levels of CRP1 protein expression were probed by Western blot analysis $2 \mathrm{~d}$ after transfection. GAPDH served as a loading control. The exogenous CRP1 was tagged with GFP. When wtCRP1 was cotransfected with shCRP1, shCRP1 not only reduced the endogenous CRP1 expression but also that of the exogenous CRP1. However, when smCRP1 was cotransfected with shCRP1, only endogenous CRP1 expression was decreased. C, shCRP1 reduces the expression of endogenous CRP1 in hippocampal neurons. Primary hippocampal neurons were transfected with control shRNA or shCRP1 plasmids and cultured for $72 \mathrm{~h}$. The expression
CRP1 in filopodia formation was also investigated in COS-7 cells by cotransfection with Cdc42, a small GTPase involved in filopodia formation (for review, see Luo, 2002). COS-7 cells are a good model for studying filopodia formation because of the low background of filopodia formation and ability to induce filopodia formation by activation of the Cdc42 pathway (Miki et al., 1998; Luo, 2002; Gauthier-Campbell et al., 2004). Consistent with previous reports (Miki et al., 1998; Gauthier-Campbell et al., 2004), overexpression of a constitutively active form of $\mathrm{Cdc} 42$ (caCdc42) promoted filopodia formation in COS-7 cells (Fig. 5). Although overexpression of CRP1 alone did not affect filopodia formation in COS-7 cells, cotransfection of both CRP1 and the constitutively active form of $\mathrm{Cdc} 42$ increased the percentage of cells with filopodia when compared with cells transfected with constitutively active Cdc42 alone (Fig. 5). These results suggest that $\mathrm{Cdc} 42$ may regulate CRP1 during the formation of filopodia. Next, we studied whether CRP1 is essential for Cdc42-induced filopodia formation using CRP1 siRNA. When COS-7 cells were cotransfected with CRP1 siRNA and constitutively active Cdc42, knockdown of CRP1 expression did not affect filopodia formation induced by $\mathrm{Cdc} 42$ (caCdc42 plus control siRNA, $12.6 \pm 1.1 \%$; caCdc42 plus CRP1 siRNA, $12.3 \pm 1.8 \% ; n=3$ experiments; $t$ test, $p>0.05$ ), indicating that CRP1 is not a necessary component for this phenomenon. However, these observations suggest a role for CRP1 in the stabilization of filopodia rather than filopodia formation. Differences in the ability of CRP1 expression to affect filopodia morphology in neurons and COS-7 cells are likely caused by cell-type variations. Additional studies

$\leftarrow$

level of endogenous CRP1 was examined by Western blot analysis. GAPDH served as a loading control. D, Knockdown of endogenous CRP1 inhibits dendritic growth of hippocampal neurons. The morphology of neurons was analyzed $3 \mathrm{~d}$ after transfection by nucleofector. Neurons transfected with shCRP1 (middle) have less dendrites when compared with neurons transfected with control shRNA (left). Cotransfection with smCRP1 (D-J) rescues the inhibition of shCRP1 on dendritic growth. $\boldsymbol{E}-\boldsymbol{J}$, Knockdown of CRP1 decreases the number of primary neurites $(\boldsymbol{E})$, the number of neurite branches $(\boldsymbol{F})$, and the number of filopodia $(\boldsymbol{G})$. The inhibitory effect of shCRP1 on total length of neurites $(\boldsymbol{H})$ is mainly attributable to inhibition on dendritic length $(\boldsymbol{I})$ but not axonal length $(\boldsymbol{J})$. Cotransfection with smCRP1 rescues the inhibited dendritic growth induced by $\operatorname{shCRP1}(\boldsymbol{E}-\boldsymbol{J}) . \boldsymbol{B}, \boldsymbol{C}, n=3$ experiments; $\boldsymbol{D}-\boldsymbol{J}, n=45$ neurons; ${ }^{*} p<0.05$, one-way ANOVA with Tukey's post hoc test; mean values \pm SEM are shown. Scale bar, $50 \mu \mathrm{m}$. 

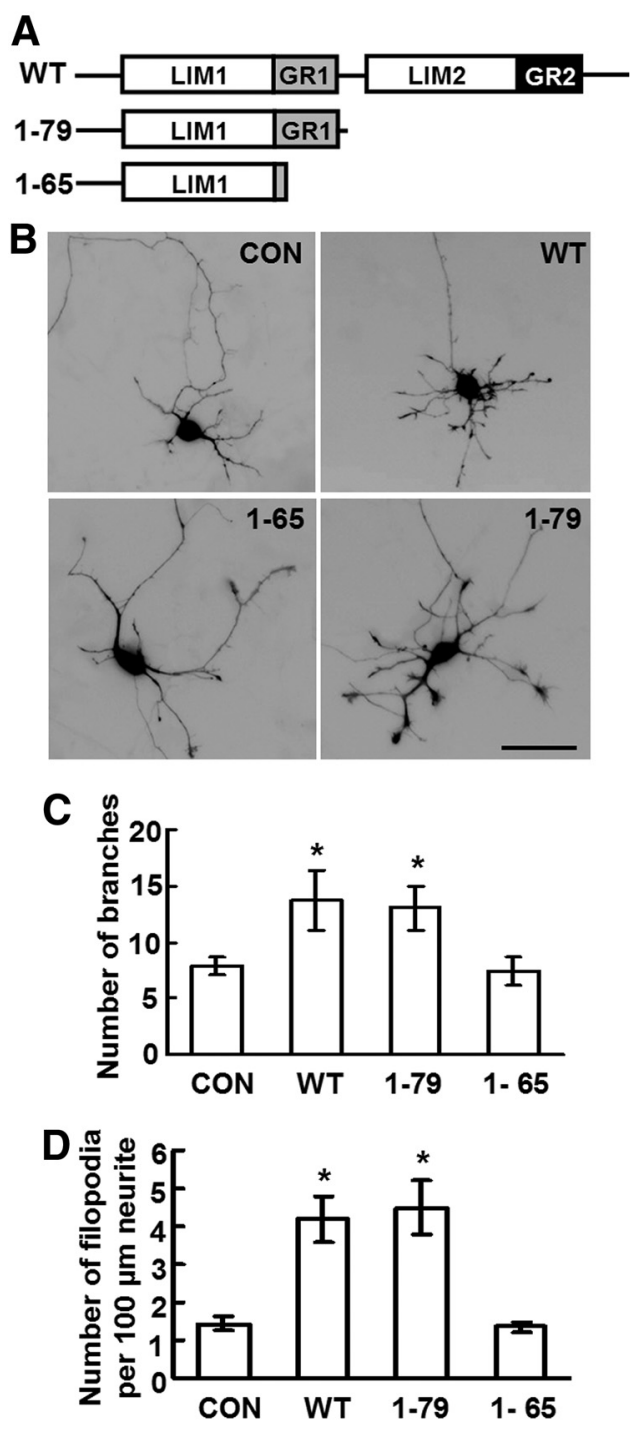

Figure 4. Actin-bundling activity is required for the role of CRP1 in neurite growth. A, Diagram of wild-type (WT) CRP1 and truncated forms of CRP1 used in this study. Whereas residues 1-79 of CRP1-containing LIM1 and GR1 domains retain actin-bundling ability and localization to the actin cytoskeleton, residues 1-65 containing LIM1 domain only do not. $\boldsymbol{B}$, Representative images of the neurons transfected with wild-type CRP1, residues 1-65, or 1-79 residue constructs. Hippocampal neurons were transfected immediately after dissociation, and neuronal morphology was analyzed $3 \mathrm{~d}$ later. $C, D$, The actin-bundling ability of CRP 1 is required for its effect on neurite branching and filopodia formation in neurons. Overexpression of residues 1-79 increases the number of neuritic branches $(\boldsymbol{C})$ and filopodia $(\boldsymbol{D})$, as well as the wild-type CRP1, whereas overexpression of residues $1-65$ does not show an enhanced effect. $n=60$ neurons; ${ }^{*} p<0.05$, one-way ANOVA with Tukey's post hoc test; mean values \pm SEM are shown. Scale bars, $50 \mu \mathrm{m}$.

are needed to determine the relationship between CRP1 and Cdc42.

\section{CRP1 is upregulated by $\mathrm{Ca}^{2+}$ influx after depolarization and} is required for $\mathrm{Ca}^{2+}$-dependent dendritic growth

Filopodia formation is required for dendritic arborization, which is essential for neuronal connectivity on which an optimally functioning nervous system is based. The role for neuronal activity in the control of dendrite arborization has been implicated in multiple neuronal systems, both during and after development. $\mathrm{Nu}-$ merous studies have shown that a $\mathrm{Ca}^{2+}$-dependent pathway is activated by neuronal activity and mediates the activity-induced changes in dendrite structure, which require changes in gene transcription (for review, see Redmond, 2008). Although several transcriptional mechanisms have been identified for the $\mathrm{Ca}^{2+}$ dependent dendritic arborization, few transcriptionally regulated effectors have been reported. In smooth muscle cells, CRP1 expression is increased after depolarization induced by high $\mathrm{K}^{+}$ (Najwer and Lilly, 2005), suggesting that CRP1 may be involved in postdepolarization modifications. Because our data showed that CRP1 is required for dendritic growth in neurons, we hypothesized that CRP1 may act as a mediator for dendritic growth induced by $\mathrm{Ca}^{2+}$ influx. It has been reported that when neurons were depolarized with $\mathrm{KCl}$ at $3 \mathrm{DIV}$, enhanced dendritic growth is observed in both cortical neurons and hippocampal neurons (Redmond et al., 2002; Tan et al., 2010). We first measured CRP1 expression in cultured hippocampal neurons after depolarization using the same condition as reported previously (Redmond et al., 2002). CRP1 mRNA levels were studied at different time points after addition of $\mathrm{KCl}$. Six hours after the addition of $\mathrm{KCl}, \mathrm{CRP1}$ mRNA expression was slightly decreased but was then upregulated from $12 \mathrm{~h}$ onward (Fig. $6 \mathrm{~A}$ ), continuing up to $48 \mathrm{~h}$ after $\mathrm{KCl}$ addition. Increases in CRP1 protein levels were also observed $48 \mathrm{~h}$ after addition of $\mathrm{KCl}$ (Fig. $6 \mathrm{~B}$ ).

To investigate whether $\mathrm{Ca}^{2+}$ influx is required for the upregulation of CRP1 induced by $\mathrm{KCl}$ stimulation, neurons were treated with EGTA, an extracellular $\mathrm{Ca}^{2+}$ chelator, with or without $\mathrm{KCl}$. As reported, 2 mM EGTA did not show any effect on cell viability on neurons (Tai et al., 2008). When cells were treated with $\mathrm{KCl}$ in the presence of EGTA, upregulation of CRP1 mRNA was blocked (Fig. 6C). This observation suggests that $\mathrm{Ca}^{2+}$ mediates the depolarization influence on CRP1 mRNA expression. In neurons, two primary $\mathrm{Ca}^{2+}$ channels, namely NMDA receptors and voltage-sensitive $\mathrm{Ca}^{2+}$ channels (L-VSCCs), mediate $\mathrm{Ca}^{2+}$ influx (Ghosh and Greenberg, 1995; Redmond et al., 2002). To address which type of $\mathrm{Ca}^{2+}$ channel is responsible for the $\mathrm{Ca}^{2+}$ dependent upregulation of CRP1 mRNA, the inhibitors APV (for NMDA receptors) and nifedipine (for L-VSCCs) were tested. In the presence of $\mathrm{KCl}$, both inhibitors reduced the upregulation of CRP1 mRNA levels (Fig. 6D). Although nifedipine was more effective than APV, upregulation of CRP1 mRNA was completely blocked only when both APV and nifedipine were applied together (Fig. 6D). Together, these data show that $\mathrm{Ca}^{2+}$ mediates the increase in CRP1 expression after depolarization.

We next studied whether CRP1 is involved in $\mathrm{Ca}^{2+}$. dependent dendritic growth. Hippocampal neurons were transfected with control shRNA or shCRP1 at 2 DIV and treated with $\mathrm{KCl}$ at $3 \mathrm{DIV}$. Neuronal morphology was examined at $5 \mathrm{DIV}$. shCRP1 reduced total dendritic length and total number of dendritic tips when compared with control shRNA (Fig. 6E-G). Consistent with the results obtained by other groups (Redmond et al., 2002; Yu and Malenka, 2003; Wayman et al., 2006; Tai et al., 2008), $\mathrm{KCl}$ treatment increased both the total dendritic length and total number of dendritic tips in neurons transfected with control shRNA (Fig. 6E-G). However, knockdown of CRP1 expression with shCRP1 inhibited the dendritic growth induced by $\mathrm{KCl}$ (Fig. $6 E-G$ ), suggesting that CRP1 is required for the influence of $\mathrm{Ca}^{2+}$ on dendritic growth. As expected, shCRP1 significantly reduced the expression of CRP1 after $\mathrm{KCl}$ stimulation, however, with a slightly lower efficacy compared with that of the unstimulated group (Fig. $6 H, I$ ). The inhibitory effect of shCRP1 on $\mathrm{Ca}^{2+}$-dependent dendritic growth was not complete, possibly because of the lower efficacy of the shCRP1 after $\mathrm{KCl}$ stimulation and/or the involvement of additional molecules other than CRP1 in this process. 
A
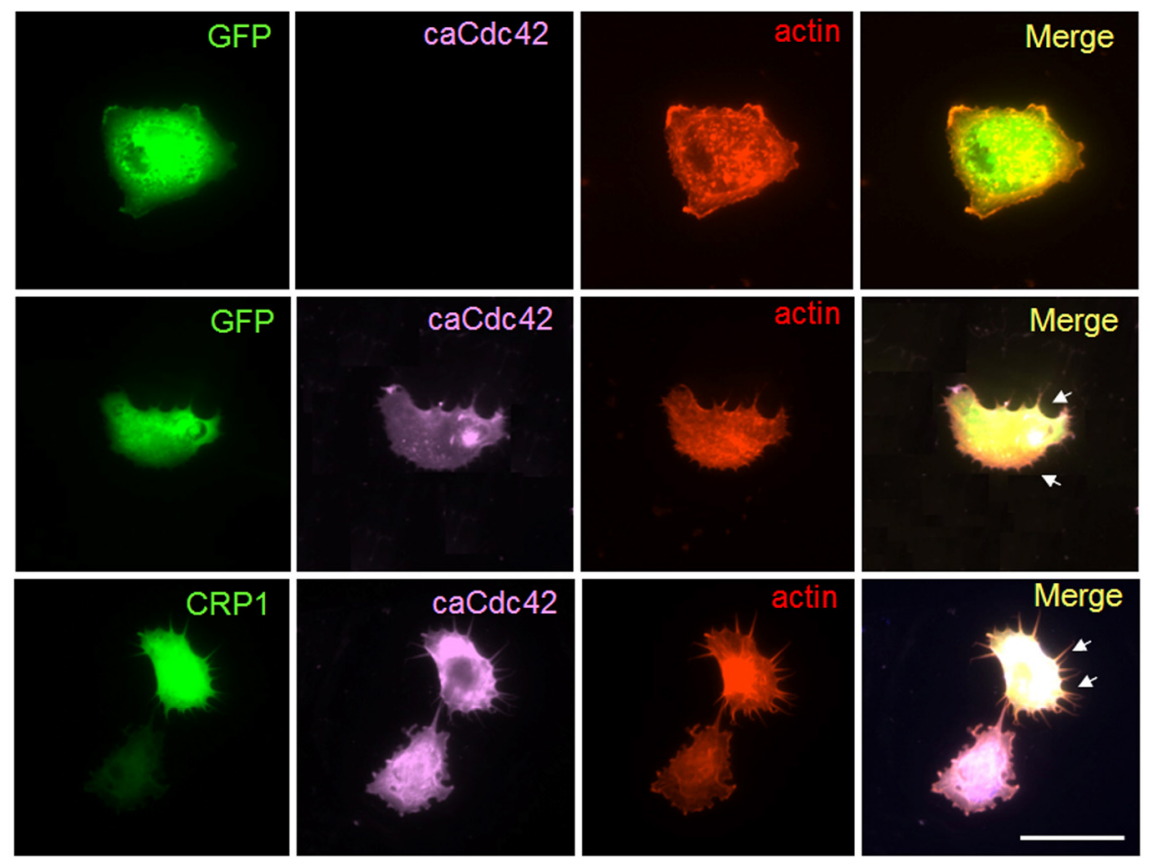

B

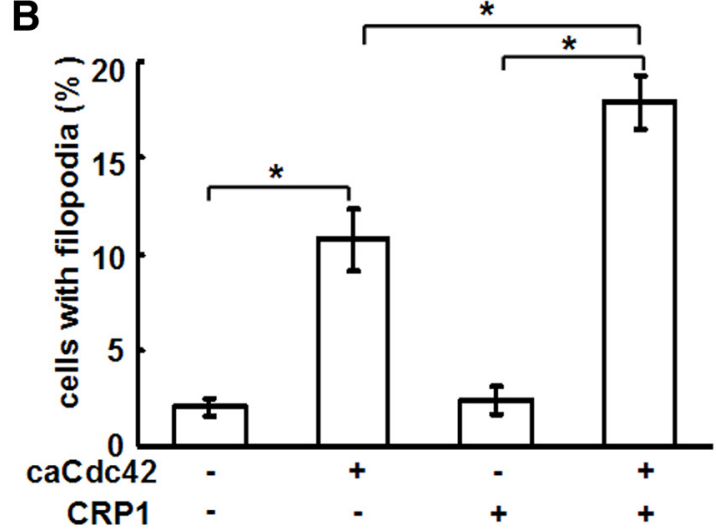

Figure 5. Cotransfection of CRP1 and constitutively active $\mathrm{Cdc} 42$ (caCdc42) increases the percentage of cells with filopodia. $\boldsymbol{A}$, COS-7 cells were transfected with GFP control vector alone, GFP-CRP1 alone, cotransfected with GFP control vector and myc-tagged $\mathrm{CaCdc42}$, or cotransfected with GFP-CRP1 and caCdc42. B, The cells were fixed $48 \mathrm{~h}$ after transfection and stained with actin and myc. In COS-7 cells, transfection of caCdc42 alone induces filopodia formation (arrows) in $\sim 10 \%$ of all cells, whereas cotransfection of caCdc42 and CRP1 increases the percentage of cells with filopodia to $18 \% . n=3$ experiments; ${ }^{*} p<0.05$, two-way ANOVA with Tukey's post hoc test; mean values \pm SEM are shown. Scale bar, $50 \mu \mathrm{m}$.

\section{CaMKIV and CREB mediate the $\mathrm{Ca}^{2+}$-induced upregulation of CRP1 expression}

$\mathrm{Ca}^{2+}$ influx activates several different pathways that mediate the transcription of different target genes. To analyze biochemical mechanisms underlying the $\mathrm{Ca}^{2+}$-induced upregulation of CRP1 expression, three primary signaling intermediates for the $\mathrm{Ca}^{2+}$ signaling pathway in neurons were studied: $\mathrm{Ca}^{2+}$ / calmodulin-dependent protein kinases (CaMKI, II, and IV), mitogen-activated protein kinase (MAPK), and protein kinase A (PKA) (Ghosh and Greenberg, 1995; Redmond et al., 2002). An inhibitor of MAPK (U0126) did not affect CRP1 mRNA levels when used alone or together with $\mathrm{KCl}$ compared with the control groups (Fig. 7B). However, KN62, an inhibitor of all CaM kinases, completely blocked the upregulation of CRP1 mRNA induced by $\mathrm{KCl}$ stimulation (Fig. $7 A$ ). Inhibiting PKA activation (KT5720), on the other hand, increased CRP1 mRNA expression (Fig. 7C), suggesting that PKA activation inhibits CRP1 expres- sion. The inhibition effect of PKA activation may explain the slightly decreased expression level of CRP1 at $6 \mathrm{~h}$ after $\mathrm{KCl}$ treatment. Six hours after $\mathrm{KCl}$ treatment, the inhibitory PKA pathway might be stronger than the promotion of the CaM kinase pathway, in agreement with the observation that enhanced expression of CRP1 is not observed at early time points. Later, the activity of the CaM kinase pathway increases and leads to the upregulation of CRP1 expression. Interestingly, these two pathways similarly affect dendritic growth and CRP1 expression induced by $\mathrm{Ca}^{2+}$ (Redmond et al., 2002).

Of the three CaM kinases found in neurons (CaMKI, II, and IV), only the roles of CaMKII and CaMKIV were analyzed since the MAPK pathway, the major downstream mediator of CaMKI (Wayman et al., 2006), did not affect CRP1 expression. To determine the CaM kinase responsible for $\mathrm{Ca}^{2+}$-dependent regulation of CRP1 expression, constitutively active forms of CaMKII and CaMKIV were used as described previously (Sun et al., 1994). Considering the limitations regarding transfection of cultured primary neurons, such as the age of cultured neurons (only freshly dissociated neurons can be used with nucleofector), the efficiency of transfection and protein expression, and the time window for upregulation of CRP1 induced by overexpression of the active forms of CaMKII or CaMKIV, we used the mouse neuroblastoma cell line N2a for this experiment. Similar to what was observed in primary culture of neurons, $\mathrm{KCl}$ stimulation also induced upregulation of CRP1 mRNA levels in $\mathrm{N} 2 \mathrm{a}$ cells (Fig. 7D). The constitutively active CaMKIV, but not caCaMKII, increased CRP1 mRNA expression (Fig. 7D). The role of CaMKIV was confirmed by using a dominant-negative form of CaMKIV (Lemrow et al., 2004), which blocked the upregulation of CRP1 mRNA levels induced by $\mathrm{KCl}$ (Fig. 7E). It has been shown that whereas CaMKIV promotes dendritic growth, CaMKII inhibits dendritic growth (Redmond et al., 2002), supporting the observation that CRP1 is required for $\mathrm{Ca}^{2+}$-dependent dendritic growth.

CREB is the best-characterized transcription factor target of CaMKIV (Matthews et al., 1994; Sun et al., 1994, 1996). CaMKIV phosphorylation of CREB activates the transcription of genes important for activity-dependent or CaMKIV-dependent dendritic growth (Redmond et al., 2002; Redmond, 2008; Tai et al., 2008). We thus investigated whether CREB mediates upregulation of CRP1 using a dominant-negative mutant of CREB (KCREB) (Walton et al., 1992). As shown in Figure 7F, CaMKIV-induced upregulation of CRP1 expression was suppressed by KCREB expression. Similarly, KCREB also blocked the stimulation of $C R P 1$ expression by $\mathrm{KCl}$ (Fig. $7 F$ ). These results demonstrate that CaMKIV and CREB activity are required for $\mathrm{Ca}^{2+}$-induced upregulation of CRP1 expression. 


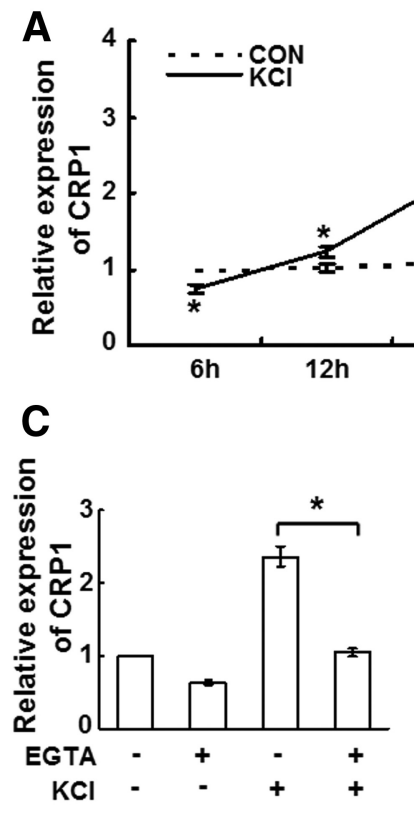

E
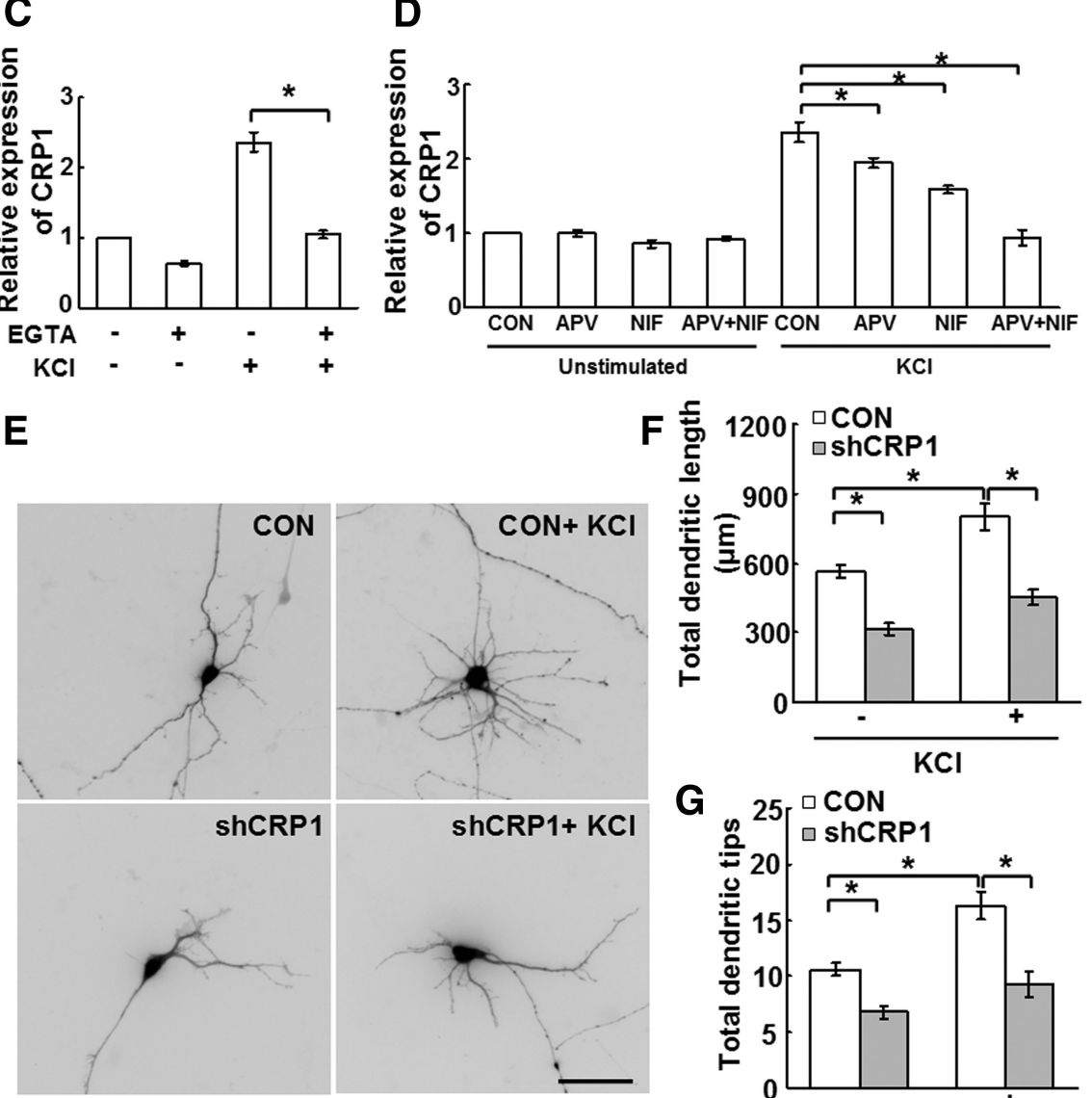

H

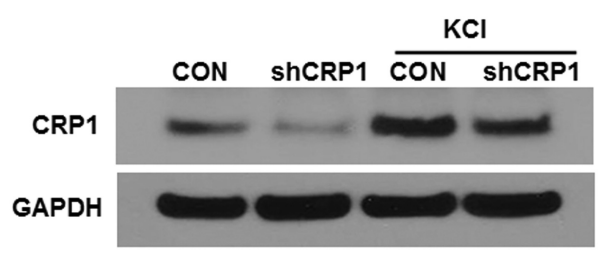

B
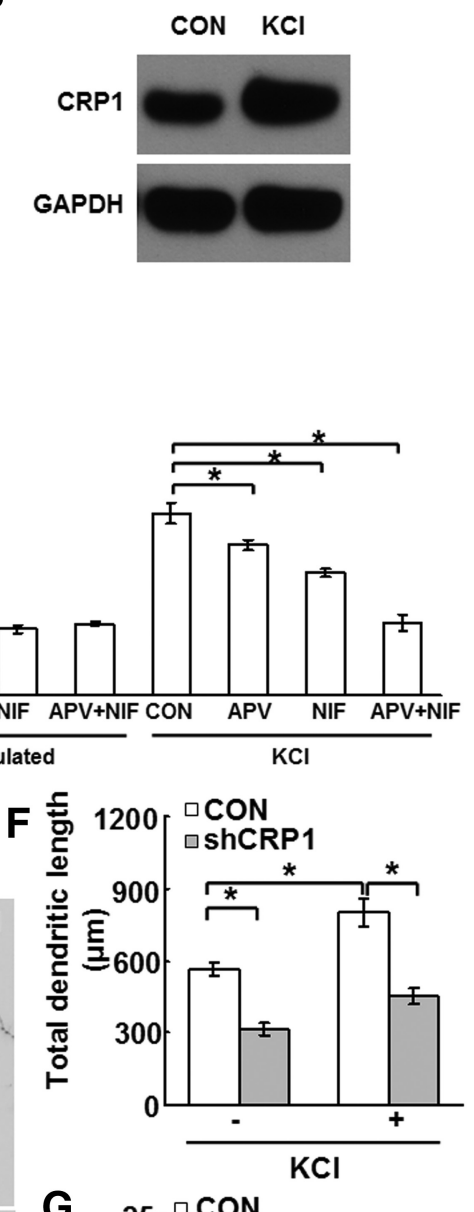

G

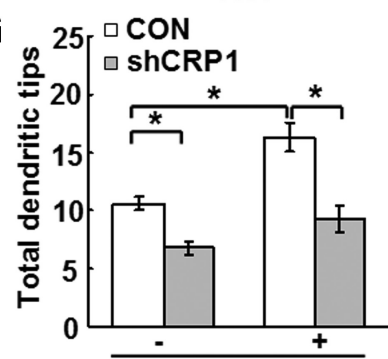

I

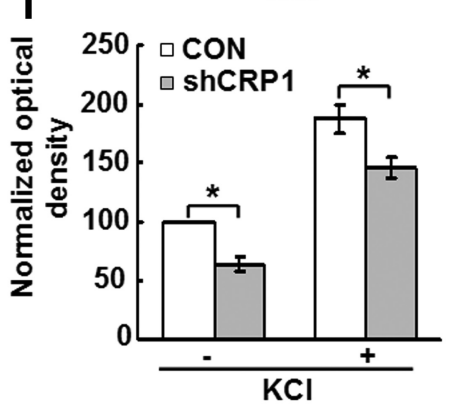

Figure 6. CRP1 is upregulated by $\mathrm{Ca}^{2+}$ influx in hippocampal neurons and is involved in $\mathrm{Ca}^{2+}$-dependent dendritic growth. $\boldsymbol{A}$, Depolarization induced by $50 \mathrm{~mm}$ KCl increases CRP1 mRNA expression. CRP1 mRNA expression is slightly downregulated at $6 \mathrm{~h}$ but is then upregulated from $12 \mathrm{~h}$, and this upregulation continues up to 24 and $48 \mathrm{~h}$. $\boldsymbol{B}, \mathrm{KCl}$ stimulation increases CRP1 protein expression as probed by Western blot analysis $48 \mathrm{~h}$ after addition of $\mathrm{KCl}$. GAPDH served as a loading control. C, EGTA (2 mM) treatment blocks the upregulation by $\mathrm{KCl}$ on $C R P 1 \mathrm{mRNA}$ levels. $\boldsymbol{D}$, Upregulation of CRP1 mRNA expression is completely blocked only when both inhibitors for L-VSCCS (NIF, nifedipine) and NMDA receptors (APV) were applied together. $\boldsymbol{E}$, Representative images of neurons transfected at 2 DIV with shCRP1 or CON and treated with or without $50 \mathrm{~mm} \mathrm{KCl}$ at 3 DIV for $48 \mathrm{~h}$. F, G, Quantification of total dendritic length $(\boldsymbol{F})$ and total number of dendritic tips $(\boldsymbol{G})$ of neurons in $\boldsymbol{E}$ shows that CRP1 is required for $\mathrm{Ca}^{2+}$-dependent dendritic growth. $\boldsymbol{H}, \boldsymbol{I}$, Hippocampal neurons were transfected with control shRNA or shCRP1 immediately after dissociation. Transfected neurons were treated with KCl at 3 DIV for $2 \mathrm{~d}$. Then, neurons were lysed for Western blot analysis $(\boldsymbol{H})$, and CRP1 protein

CaMKIV mediates the dendritic growth induced by $\mathrm{Ca}^{2+}$, and caCaMKIV is sufficient to increase dendritic growth (Redmond et al., 2002; Yu and Malenka, 2003; Tai et al., 2008). Since caCaMKIV increased CRP1 expression, we studied whether CRP1 contributes to CaMKIV-induced dendritic growth using shCRP1. Consistent with previous work (Redmond et al., 2002; Yu and Malenka, 2003; Tai et al., 2008), overexpression of caCaMKIV indeed increased dendritic growth as measured by dendritic length and total number of dendritic tips (Fig. 7 G-I). Knockdown of CRP1 expression significantly inhibited the dendritic growth induced by caCaMKIV (Fig. 7G-I). Together, these results support the view that the upregulation of CRP1 is regulated by the CaMKIV and CREB pathways and that CRP1 is required for CaMKIV-dependent dendritic growth.

\section{Discussion}

As the most widely expressed member of the CRP family, CRP1 has been associated with various cell activities. The amino acid sequence of CRP1 is similar among vertebrates with $>80 \%$ identity between human, mouse, rat, chicken, quail, and zebrafish, suggesting conservation of function (McLaughlin et al., 1994). Our study presents a novel functional role for CRP1 in the CNS as an actin-bundling protein involved in the formation of filopodia in neurons. In cultured primary rat neurons, endogenous CRP1 accumulates in the growth cone and colocalizes with actin filaments in filopodia. In contrast, colocalization with actin filaments was not observed in non-neuronal cells, suggesting that CRP1 functions differently, depending on the cell type. This is confirmed by the different effects of CRP1 on filopodia formation in COS-7 cells compared with that in neurons. Although expression of

was quantified by densitometry (I). (RP1 is knocked down by $35 \%$ in unstimulated neurons transfected with shCRP1 (unstimulated control shRNA is $100 \%)$. However, in $\mathrm{KCl}$ stimulated neurons, shCRP1 is observed to knockdown CRP1 protein by $22 \%$ (stimulated control shRNA is $100 \%$ ). Thus, shCRP1 decreases (RP1 expression after KCl stimulation, with a slightly lower efficacy compared with that of unstimulated neurons. Since the transfection efficiency was $\sim 40 \%$, we estimate that $60 \%$ of the cells were untransfected and responded to $\mathrm{KCl}$ treatment by upregulating CRP1 in the stimulated shCRP1 group. $\boldsymbol{A}-\boldsymbol{D}, \boldsymbol{H}, \boldsymbol{I}, n=3$ experiments; $\boldsymbol{E}-\boldsymbol{G}$, $n=60$ neurons; ${ }^{*} p<0.05, t$ test $(A, I)$ and two-way ANOVA with Tukey's post hoc test $(\boldsymbol{C}, \boldsymbol{D}, \boldsymbol{F}, \boldsymbol{G})$; mean values \pm SEM are shown. Scale bar, $50 \mu \mathrm{m}$. Hippocampal neurons at 3 DIV were treated with $\mathrm{KCl}$, and expression of CRP1 was determined at different time points $(\boldsymbol{A})$ or $48 \mathrm{~h}(\boldsymbol{B})$ or $24 \mathrm{~h}(\boldsymbol{C}, \boldsymbol{D})$ after addition of $\mathrm{KCl}$. 
A

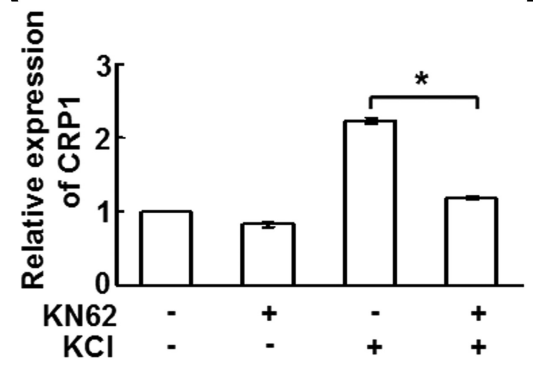

C

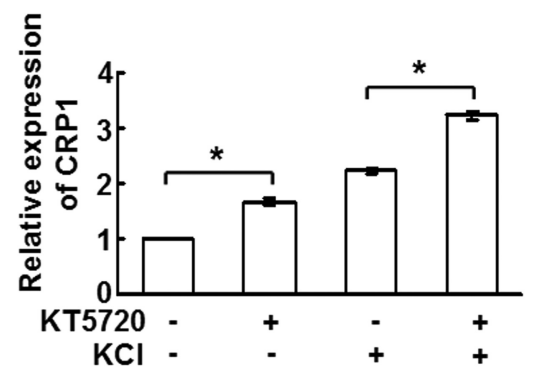

E

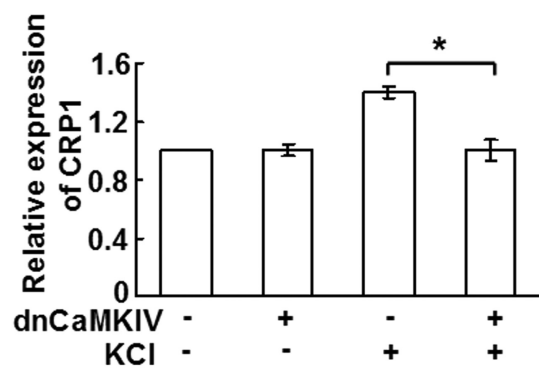

G

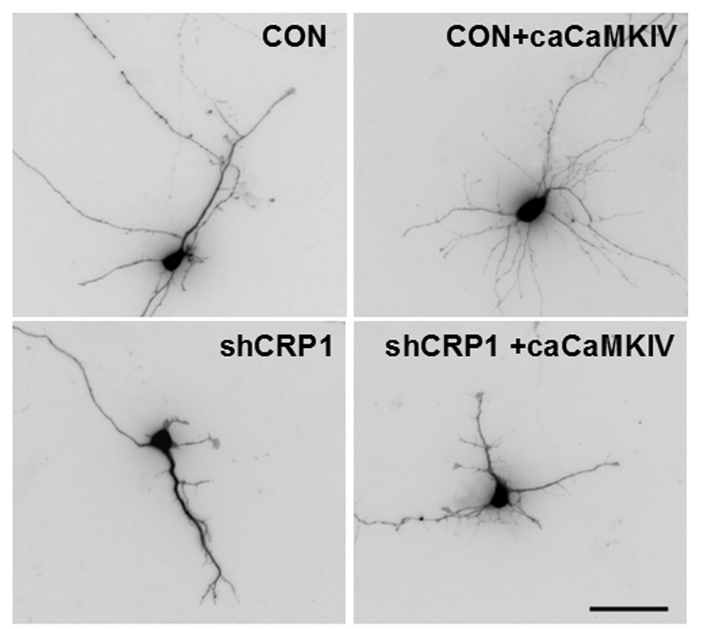

B

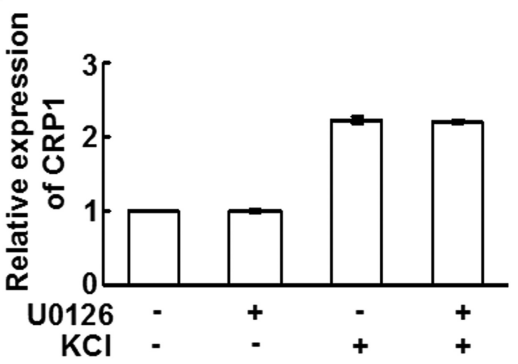

D

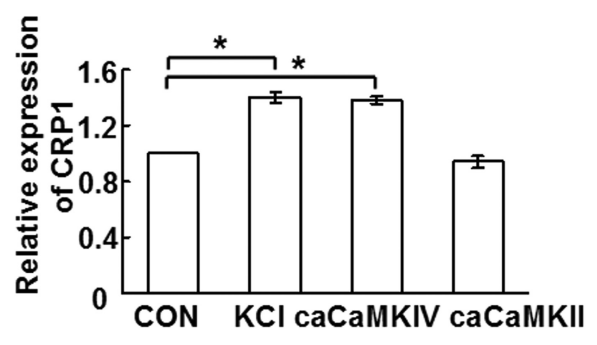

$\mathbf{F}$

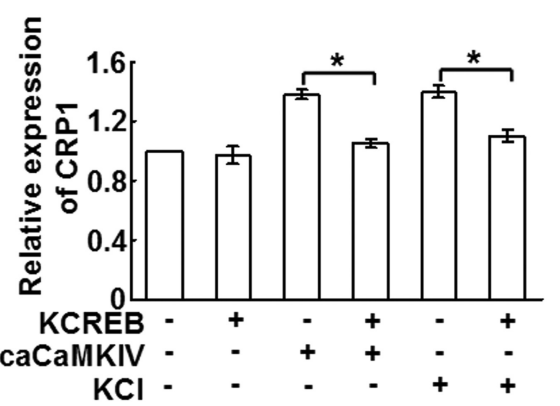

$\mathrm{H}$

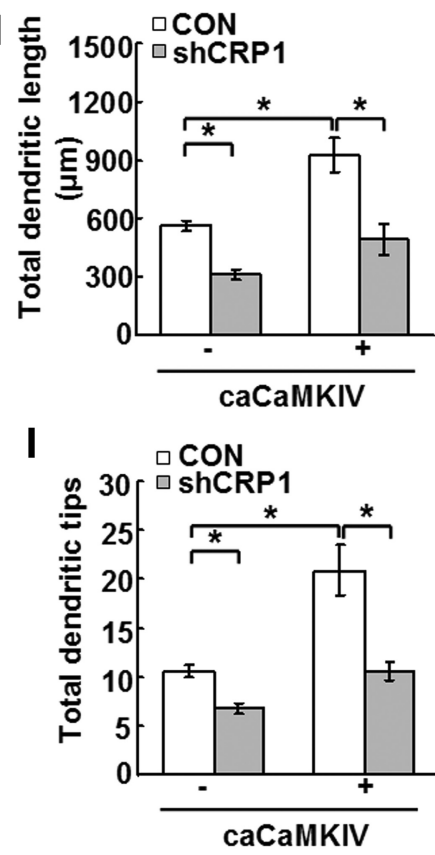

Figure 7. CaMKIV and CREB mediate the upregulation of CRP1 induced by KCI. $\boldsymbol{A}$, The inhibitor of CaM kinases, KN62, completely blocks the upregulation of $C R P 1 \mathrm{mRNA}$ induced by $\mathrm{KCl}$. $\boldsymbol{B}$, The inhibitor of MAP kinase, U0126, does not influence expression of CRP1 mRNA. MAPK is not involved in the upregulation of CRP1 mRNA induced by KCI. C, The inhibitor of PKA, KT5720, increases CRP1 mRNA expression. D, E, CaMKIV, but not CaMKII, mediates the upregulation of CRP1 mRNA expression. In N2a cells, KCI treatment also increased CRP1 mRNA expression. Constitutively active forms of CaMKIV (caCaMKIV) and CaMKII (caCaMKII) were used, and

CRP1 was sufficient to induce filopodia formation in neurons, CRP1 did not induce filopodia formation in COS-7 cells. When we compared the biological characteristics of neurons with that of COS-7 cells, it is noteworthy that filopodia formation is always active in the former but not the latter, which may indicate a difference in the activation status of the pathways involved in filopodia formation. This view is confirmed by the evidence showing that cotransfection of CRP1 with a constitutively active form of Cdc42 increased filopodia formation in COS-7 cells. Thus, CRP1 is specifically involved in filopodia formation in neurons in the CNS.

Localization of CRP1 to the filopodia of growth cones in neurons is consistent with previous observations that CRP1 directly interacts with actin filaments and functions as an actin bundling protein (Tran et al., 2005; Jang and Greenwood, 2009). Moreover, the localization of CRP1 is similar to that of fascin, another actinbundling protein involved in filopodia formation, in that it is localized along the entire length of filopodia (Cohan et al., 2001; Vignjevic et al., 2006), further suggesting that CRP1 serves an important role in filopodia formation. Using different truncated forms of CRP1, we showed that amino acid residues $1-79$ retain actin-bundling activity and mimic the effect of wild-type CRP1, whereas residues 1-65, which have no bundling activity, did not affect neuronal morphology. This finding supports the conclusion that the actin-bundling activity of CRP1 is required, at least partly, for neurite growth. In addition, loss-of-function and gain-of-

$\leftarrow$

only caCaMKIV increased CRP1 mRNA levels (D). The ability of CaMKIV to increase CRP1 mRNA levels was also confirmed by showing that a dominant-negative form of CaMKIV (dnCaMKIV) blocks the upregulation by $\mathrm{KCI}(\boldsymbol{E})$. $\boldsymbol{F}$, CREB mediates the upregulation of CRP $1 \mathrm{mRNA}$ induced by CaMKIV or KCI. G, Representative images of neurons cotransfected at 2 DIV with caCaMKIV and either shCRP1 or control shRNA at a ratio of 3:1 and fixed at 5 DIV. $\boldsymbol{H}, \boldsymbol{I}$, Quantification of total dendritic length $(\boldsymbol{H})$ and total number of dendritic tips $(\boldsymbol{I})$ of neurons $(\boldsymbol{G})$ shows that CRP1 is required for CaMKIV-dependent dendritic growth. $A--\boldsymbol{F}, n=3$ experiments; $\boldsymbol{G}-\boldsymbol{I}, n=45$ neurons; ${ }^{*} p<0.05$, one-way ANOVA with Tukey's post hoc test $(\boldsymbol{D})$ and two-way ANOVA with Tukey's post hoc test $(\boldsymbol{A}-\boldsymbol{C}, \boldsymbol{E}, \boldsymbol{F}, \boldsymbol{H}-\boldsymbol{l})$; mean values \pm SEM are shown. Scale bars, $50 \mu \mathrm{m}$. Primary neurons at 3 DIV were treated as indicated, and the expression of CRP1 mRNA was examined $24 \mathrm{~h}$ later ( $\boldsymbol{A}-\boldsymbol{C}$ ). For $\boldsymbol{D}-\boldsymbol{F}$, N2a cells were transfected with different vectors, and the expression of CRP1 mRNA was examined $2 \mathrm{~d}$ later. The N2a cells were treated with $50 \mathrm{~mm} \mathrm{KCl} 24 \mathrm{~h}$ after transfection, and the expression of CRP1 mRNA was examined $24 \mathrm{~h}$ after $\mathrm{KCl}$ stimulation. The cotransfection of CaCaMKIV and KCREB was performed at a ratio of 1:2. 
function experiments demonstrate an essential role of CRP1 in filopodia formation, in which it regulates neuritogenesis, neurite elongation, and neurite branching. Whether other functions of CRP1, such as transcriptional regulation (Chang et al., 2003), are involved in its role in neurite growth will require further investigation.

In vitro, knockdown of endogenous CRP1 in cultured hippocampal neurons inhibited filopodia formation and dendritic growth. This characteristic is similar to that of other molecules, such as Ena/vasodilator-stimulated phosphoprotein (VASP) (Lebrand et al., 2004; Dent et al., 2007), MARCKs (myristoylated, alanine-rich C kinase substrate) (Calabrese and Halpain, 2005; Li et al., 2008), TRPC6 (transient receptor potential channel 6) (Tai et al., 2008; Zhou et al., 2008), and septin 7 (Xie et al., 2007), all of which are needed not only for filopodia or spine formation but also for dendritic growth. Since filopodia are not only essential for neurite outgrowth but also develop into dendritic spines (Yuste and Bonhoeffer, 2004; Mattila and Lappalainen, 2008), it is not surprising that proteins involved in filopodia formation also contribute to spine formation. Our study shows that knockdown of CRP1 reduces the number of primary neurites, demonstrating a role for CRP1 in neuritogenesis. The essential role of filopodia in neuritogenesis has been demonstrated by experiments showing that knockdown of Ena/VASP, proteins involved in filopodia formation, causes defects in neurite initiation and thus neurite formation in cortical neurons (Dent et al., 2007). Moreover, many fine filopodial protrusions rapidly extend and retract on the dendritic shafts of hippocampal neurons during early dendritic development, directly transforming into nascent dendritic branches, suggesting that neurite branching is also initiated by filopodia (Dailey and Smith, 1996; Lalli and Hall, 2005; Hall and Lalli, 2010). Thus, these data support our observation that CRP1 affects neuritogenesis and neurite branching via its function in filopodia formation. Furthermore, filopodia formation is also among the first structural changes to occur at the regrowing axon tip and is required for growth cone formation after injury (Welnhofer et al., 1997), suggesting a potential role for CRP1 in regeneration after injury.

A number of studies have shown that neuronal activity regulates dendritic architecture and that $\mathrm{Ca}^{2+}$ influx is a critical primary event in this response (for review, see Redmond, 2008). New protein synthesis is required for activity-dependent dendritic growth, and gene transcription mediated by CREB plays a key role in this process (Redmond et al., 2002; Redmond, 2008). Although $\mathrm{Ca}^{2+}$-dependent dendritic growth requires CREBmediated transcription, little is known about the target genes of $\mathrm{Ca}^{2+}$ activity that mediate dendritic growth. One potential target is brain-derived neurotrophic factor, which is upregulated by $\mathrm{Ca}^{2+}$ influx into primary neurons (Ghosh et al., 1994). Another secreted protein, Wnt-2, is upregulated in neurons after depolarization and mediates activity-induced dendritic growth (Wayman et al., 2006). Here, we found that CRP1 expression is not only upregulated by $\mathrm{Ca}^{2+}$ influx into neurons but is also required for $\mathrm{Ca}^{2+}$-dependent dendritic growth. Consistent with this, similar intracellular signaling molecules are shared by CRP1 expression and dendritic growth induced by $\mathrm{Ca}^{2+}$ influx (Redmond et al., 2002). Activation of PKA inhibits dendritic growth as well as the expression of CRP1, whereas CaMKIV mediates $\mathrm{Ca}^{2+}$ dependent dendritic growth and increases CRP1 expression. Together, upregulation of CRP1 significantly contributes to $\mathrm{Ca}^{2+}$-dependent dendritic growth not only during development but also in activity-induced remodeling of synaptic connections in the adult. Whether recognition molecules at the cell surface and/or in the extracellular matrix guide this formation of axonal and/or dendritic filopodia via triggering CRP1 activities remains to be investigated. Preliminary results (data not shown) indicate that the neurite outgrowth promoting Ig superfamily molecules L1 and NCAM are not involved.

In conclusion, we provide evidence for an essential role of CRP1 in filopodia formation and dendritic growth. CRP1 is upregulated by neuronal activity via the CaMKIV-CREB pathway and is required for $\mathrm{Ca}^{2+}$-dependent dendritic growth. Our study expands on the current knowledge regarding the functional role of CRP1 and demonstrates the importance of its function in the vertebrate CNS.

\section{References}

Arber S, Caroni P (1996) Specificity of single LIM motifs in targeting and LIM/LIM interactions in situ. Genes Dev 10:289-300.

Becker T, Bernhardt RR, Reinhard E, Wullimann MF, Tongiorgi E, Schachner M (1998) Readiness of zebrafish brain neurons to regenerate a spinal axon correlates with differential expression of specific cell recognition molecules. J Neurosci 18:5789-5803.

Calabrese B, Halpain S (2005) Essential role for the PKC target MARCKS in maintaining dendritic spine morphology. Neuron 48:77-90.

Chang DF, Belaguli NS, Iyer D, Roberts WB, Wu SP, Dong XR, Marx JG, Moore MS, Beckerle MC, Majesky MW, Schwartz RJ (2003) Cysteinerich LIM-only proteins CRP1 and CRP2 are potent smooth muscle differentiation cofactors. Dev Cell 4:107-118.

Chen H, Firestein BL (2007) RhoA regulates dendrite branching in hippocampal neurons by decreasing cypin protein levels. J Neurosci 27:8378-8386.

Cohan CS, Welnhofer EA, Zhao L, Matsumura F, Yamashiro S (2001) Role of the actin bundling protein fascin in growth cone morphogenesis: localization in filopodia and lamellipodia. Cell Motil Cytoskeleton 48:109-120.

Crozier RA, Bi C, Han YR, Plummer MR (2008) BDNF modulation of NMDA receptors is activity dependent. J Neurophysiol 100:3264-3274.

Dailey ME, Smith SJ (1996) The dynamics of dendritic structure in developing hippocampal slices. J Neurosci 16:2983-2994.

Dent EW, Kwiatkowski AV, Mebane LM, Philippar U, Barzik M, Rubinson DA, Gupton S, Van Veen JE, Furman C, Zhang J, Alberts AS, Mori S, Gertler FB (2007) Filopodia are required for cortical neurite initiation. Nat Cell Biol 9:1347-1359.

Dickson BJ (2002) Molecular mechanisms of axon guidance. Science 298:1959-1964.

Dityatev A, Dityateva G, Schachner M (2000) Synaptic strength as a function of post- versus presynaptic expression of the neural cell adhesion molecule NCAM. Neuron 26:207-217.

Dotti CG, Sullivan CA, Banker GA (1988) The establishment of polarity by hippocampal neurons in culture. J Neurosci 8:1454-1468.

Gallo G, Letourneau PC (2004) Regulation of growth cone actin filaments by guidance cues. J Neurobiol 58:92-102.

Garvalov BK, Flynn KC, Neukirchen D, Meyn L, Teusch N, Wu X, Brakebusch C, Bamburg JR, Bradke F (2007) Cdc42 regulates cofilin during the establishment of neuronal polarity. J Neurosci 27:13117-13129.

Gauthier-Campbell C, Bredt DS, Murphy TH, El-Husseini Ael D (2004) Regulation of dendritic branching and filopodia formation in hippocampal neurons by specific acylated protein motifs. Mol Biol Cell 15:2205-2217.

Ghosh A, Greenberg ME (1995) Distinct roles for bFGF and NT-3 in the regulation of cortical neurogenesis. Neuron 15:89-103.

Goff LA, Bowers J, Schwalm J, Howerton K, Getts RC, Hart RP (2004) Evaluation of sense-strand mRNA amplification by comparative quantitative PCR. BMC Genomics 5:76-84.

Hall A, Lalli G (2010) Rho and ras GTPases in axon growth, guidance, and branching. Cold Spring Harb Perspect Biol 2:a001818.

Jain MK, Kashiki S, Hsieh CM, Layne MD, Yet SF, Sibinga NE, Chin MT, Feinberg MW, Woo I, Maas RL, Haber E, Lee ME (1998) Embryonic expression suggests an important role for CRP2/SmLIM in the developing cardiovascular system. Circ Res 83:980-985.

Jang HS, Greenwood JA (2009) Glycine-rich region regulates cysteine-rich protein 1 binding to actin cytoskeleton. Biochem Biophys Res Commun 380:484-488 
Lalli G, Hall A (2005) Ral GTPases regulate neurite branching through GAP-43 and the exocyst complex. J Cell Biol 171:857-869.

Latonen L, Jarvinen PM, Laiho M (2008) Cytoskeleton-interacting LIMdomain protein CRP1 suppresses cell proliferation and protects from stress-induced cell death. Exp Cell Res 314:738-747.

Lebrand C, Dent EW, Strasser GA, Lanier LM, Krause M, Svitkina TM, Borisy GG, Gertler FB (2004) Critical role of Ena/VASP proteins for filopodia formation in neurons and in function downstream of netrin-1. Neuron 42:37-49.

Lemrow SM, Anderson KA, Joseph JD, Ribar TJ, Noeldner PK, Means AR (2004) Catalytic activity is required for calcium/calmodulin-dependent protein kinase IV to enter the nucleus. J Biol Chem 279:11664-11671.

Li H, Chen G, Zhou B, Duan S (2008) Actin filament assembly by myristoylated alanine-rich C kinase substrate-phosphatidylinositol-4,5-diphosphate signaling is critical for dendrite branching. Mol Biol Cell 19:4804-4813.

Lieberoth BC, Becker CG, Becker T (2003) Double labeling of neurons by retrograde axonal tracing and non-radioactive in situ hybridization in the CNS of adult zebrafish. Methods Cell Sci 25:65-70.

Lilly B, Clark KA, Yoshigi M, Pronovost S, Wu ML, Periasamy M, Chi M, Paul RJ, Yet SF, Beckerle MC (2010) Loss of the serum response factor cofactor, cysteine-rich protein 1, attenuates neointima formation in the mouse. Arterioscler Thromb Vasc Biol 30:694-701.

Louis HA, Pino JD, Schmeichel KL, Pomies P, Beckerle MC (1997) Comparison of three members of the cysteine-rich protein family reveals functional conservation and divergent patterns of gene expression. J Biol Chem 272:27484-27491.

Luo L (2002) Actin cytoskeleton regulation in neuronal morphogenesis and structural plasticity. Annu Rev Cell Dev Biol 18:601-635.

Matthews RP, Guthrie CR, Wailes LM, Zhao X, Means AR, McKnight GS (1994) Calcium/calmodulin-dependent protein kinase types II and IV differentially regulate CREB-dependent gene expression. Mol Cell Biol 14:6107-6116.

Mattila PK, Lappalainen P (2008) Filopodia: molecular architecture and cellular functions. Nat Rev Mol Cell Biol 9:446-454.

McLaughlin CR, Tao Q, Abood ME (1994) Isolation and developmental expression of a rat cDNA encoding a cysteine-rich zinc finger protein. Nucleic Acids Res 22:5477-5483.

Miki H, Sasaki T, Takai Y, Takenawa T (1998) Induction of filopodium formation by a WASP-related actin-depolymerizing protein N-WASP. Nature 391:93-96.

Miyasaka KY, Kida YS, Sato T, Minami M, Ogura T (2007) Csrp1 regulates dynamic cell movements of the mesendoderm and cardiac mesoderm through interactions with Dishevelled and Diversin. Proc Natl Acad Sci U S A 104:11274-11279.

Mogilner A, Oster G (1996) Cell motility driven by actin polymerization. Biophys J 71:3030-3045.

Mogilner A, Rubinstein B (2005) The physics of filopodial protrusion. Biophys J 89:782-795.

Najwer I, Lilly B (2005) Ca2+/calmodulin-dependent protein kinase IV activates cysteine-rich protein 1 through adjacent CRE and CArG elements. Am J Physiol Cell Physiol 289:C785-C793.

Pomies P, Louis HA, Beckerle MC (1997) CRP1, a LIM domain protein implicated in muscle differentiation, interacts with alpha-actinin. J Cell Biol 139:157-168.

Redmond L (2008) Translating neuronal activity into dendrite elaboration: signaling to the nucleus. Neurosignals 16:194-208.
Redmond L, Kashani AH, Ghosh A (2002) Calcium regulation of dendritic growth via CaM kinase IV and CREB-mediated transcription. Neuron 34:999-1010.

Sadler I, Crawford AW, Michelsen JW, Beckerle MC (1992) Zyxin and CCRP: two interactive LIM domain proteins associated with the cytoskeleton. J Cell Biol 119:1573-1587.

Schmeichel KL, Beckerle MC (1994) The LIM domain is a modular proteinbinding interface. Cell 79:211-219.

Schmeichel KL, Beckerle MC (1998) LIM domains of cysteine-rich protein 1 (CRP1) are essential for its zyxin-binding function. Biochem J 331:885-892.

Sun P, Enslen H, Myung PS, Maurer RA (1994) Differential activation of CREB by $\mathrm{Ca} 2+/$ calmodulin-dependent protein kinases type II and type IV involves phosphorylation of a site that negatively regulates activity. Genes Dev 8:2527-2539.

Sun P, Lou L, Maurer RA (1996) Regulation of activating transcription factor- 1 and the cAMP response element-binding protein by $\mathrm{Ca} 2+/$ calmodulin-dependent protein kinases type I, II, and IV. J Biol Chem 271:3066-3073.

Tai Y, Feng S, Ge R, Du W, Zhang X, He Z, Wang Y (2008) TRPC6 channels promote dendritic growth via the CaMKIV-CREB pathway. J Cell Sci 121:2301-2307.

Tan ZJ, Peng Y, Song HL, Zheng JJ, Yu X (2010) N-cadherin-dependent neuron-neuron interaction is required for the maintenance of activityinduced dendrite growth. Proc Natl Acad Sci U S A 107:9873-9878.

Tran TC, Singleton C, Fraley TS, Greenwood JA (2005) Cysteine-rich protein 1 (CRP1) regulates actin filament bundling. BMC Cell Biol 6:45-57.

Vignjevic D, Kojima S, Aratyn Y, Danciu O, Svitkina T, Borisy GG (2006) Role of fascin in filopodial protrusion. J Cell Biol 174:863-875.

Walton KM, Rehfuss RP, Chrivia JC, Lochner JE, Goodman RH (1992) A dominant repressor of cyclic adenosine $3^{\prime}, 5^{\prime}$-monophosphate (cAMP)regulated enhancer-binding protein activity inhibits the cAMP-mediated induction of the somatostatin promoter in vivo. Mol Endocrinol 6:647-655.

Wayman GA, Impey S, Marks D, Saneyoshi T, Grant WF, Derkach V, Soderling TR (2006) Activity-dependent dendritic arborization mediated by CaM-kinase I activation and enhanced CREB-dependent transcription of Wnt-2. Neuron 50:897-909.

Welnhofer EA, Zhao L, Cohan CS (1997) Actin dynamics and organization during growth cone morphogenesis in Helisoma neurons. Cell Motil Cytoskeleton 37:54-71

Xie Y, Vessey JP, Konecna A, Dahm R, Macchi P, Kiebler MA (2007) The GTP-binding protein Septin 7 is critical for dendrite branching and dendritic-spine morphology. Curr Biol 17:1746-1751.

Yu X, Malenka RC (2003) Beta-catenin is critical for dendritic morphogenesis. Nat Neurosci 6:1169-1177.

Yuste R, Bonhoeffer T (2004) Genesis of dendritic spines: insights from ultrastructural and imaging studies. Nat Rev Neurosci 5:24-34.

Zhang X, Zhu J, Yang GY, Wang QJ, Qian L, Chen YM, Chen F, Tao Y, Hu HS, Wang T, Luo ZG (2007) Dishevelled promotes axon differentiation by regulating atypical protein kinase C. Nat Cell Biol 9:743-754.

Zhou J, Du W, Zhou K, Tai Y, Yao H, Jia Y, Ding Y, Wang Y (2008) Critical role of TRPC6 channels in the formation of excitatory synapses. Nat Neurosci 11:741-743. 